\title{
Joanna PYPLACZ
}

\section{EL MOTÍN DE LA TIERRA LA "MAQUINARIA DIVINA" CTÓNICA EN LA FARSALIA}

\author{
THE REVOLT OF THE EARTH. \\ THE CHTHONIC DIVINE APPARATUS IN THE PHARSALIA
}

\begin{abstract}
The present article discusses the presence and function of chthonic monsters in Lucan's Pharsalia. While two of these, i.e. Antaeus and Medusa, belong to the mythical past and their function is only illustrative, Erichtho, whose name denotes "discord" and "earth", plays the role of the representative goddess of the chaos and pointlessness of the Civil War. The Thessalian witch impersonates the wrath of the Earth caused by the mutatio solis, mentioned in the invocation, and strongly connected with the Senecan motif of fuga solis. This article has revealed that line 1.49, telluremque nihil mutato sole timentem, which has been the starting point of the whole analysis, anticipates the three chthonic episodes. It has also shown, quite unexpectedly, that this particular line, by equalling rhetorically the results of Nero's apotheosis and the rise of Caesar, conveys the message that Nero is the moral successor of the same man whose actions Lucan depicts as being the trigger of the chaos described in the Phrasalia.
\end{abstract}

Keywords: Lucan, Pharsalia, Erichtho, Medusa, Antaeus

\section{Mutato sole...}

Una de las cualidades de la Farsalia de Lucano que la hace diferente a los anteriores poemas épicos es el hecho de que carezca de "maquinaria divina". Aunque el poeta menciona en varias ocasiones a los dioses tradicionales (por ejemplo en 1. 198), lo hace de una manera totalmente convencional siguiendo las leyes del lenguaje épico. En efecto, las divinidades olímpicas en su poema son, como bien ya ha escrito Frederick Ahl, silenciosas e inactivas ${ }^{1}$.

${ }^{1}$ F. Ahl, The Shadows of a Divine Presence in the Pharsalia, "Hermes" 102, 2 (1997) p. 567590, en 568. Véase también: E. Fantham, Lucan, De Bello Civili, Book II, Cambridge University Press, Cambridge 1992, p. 9; R. Sklenár,, The Taste for Nothingness. A Study of "Virtus" and Relate Themes in Lucan's "Bellum Civile”, University of Michigan Press, Ann Arbor 2003, p. 8. 
El siguiente fragmento del famoso y a la vez controversivo proemio al emperador Nerón que aparentemente se refiere a su poder y grandeza; puede sin embargo, contener ciertas ambigüedades:

[...] Te, cum statione peracta

astra petes serus, praelati regia caeli

excipiet gaudente polo: seu sceptra tenere,

seu te flammigeros Phoebi conscendere currus,

telluremque nihil mutato sole timentem

igne vago lustrare iuvet, tibi numine ab omni

cedetur, iurisque tui natura relinquet

quis deus esse velis, ubi regnum ponere mundi.

$(1.45-52)$

En el verso 49 el narrador habla de la tierra que, después de mutatio solis, ya no tiene miedo a nada (tellurem... nihil... timentem). La construcción de esta línea es muy simétrica:

telluremque nihil mutato sole timentem [...].

La construcción especial de este verso está enmarcada por las palabras tellurem y timentem en sus extremos; mientras que la expresión mutato sole se encuentra en el centro junto con la palabra nihil. De esta manera, el poeta ha acentuado el hecho de que la tierra pierde todos sus temores después de mutatio solis; es decir, después de que Nerón muera y haya sido endiosado. Ya sólo por el mero hecho de que este verso forme parte del proemio, debería ser analizado con suma atención puesto que una de las funciones básicas del proemio de un poema épico es indicar el contenido de esta obra ${ }^{2}$.

Aparentemente, la expresión mutato sole se refiere al mismo Nerón que al subirse al carro de Apolo y ascender al cielo causaría un cambio en la distancia entre el Sol y la Tierra. No obstante, esta expresión también puede anticipar, o por lo menos estar conectada con el motivo Senecano de fuga solis (Sen. Thy. 776-788; 992-995, Phae. 677-679, Med. 29-39, Ag. 908-99, 726-729, HerF. 1131-1137), el cual aparece también y con una gran frecuencia en la Farsalia.

Ya en el primer libro, Lucano menciona la cena de Tiestes y la noche de Micenas (qualem fugiente per ortus / sole Thyesteae noctem duxere Mycenae, 1. 543-544). Además de esto, habla de como la tierra rompe con sus cadenas (Tum cardine tellus / subsedit, 1. 552-553). En el cuarto libro, Lucano utiliza este mismo motivo en una descripción muy expresiva del diluvio catastrófico que atrapa al ejército Cesariano en Ilerda (4. 103-105). Asimismo, en esta descripción la oscuridad está directamen-

2 J. Bartolomé, El proemio de la Farsalia de Lucano y su recepción. I, "Cuadernos de Filología Clásica. Estudios Latinos” 29, 1 (2009), p. 25-44, en 27. 
te conectada con un extraordinario temblor de la tierra (nec Phoebum surgere sentit I nox subtexta polo, 4. 103-104; concussaque tellus, 4. 115).

La yuxtaposición del motivo de mutatio solis y del "motín de la tierra" aparece, también en el sexto libro, en un contexto muy peculiar: con un encanto mágico Erichtho amenaza a Hades con mandar el sol a través de una caverna en la tierra para llenar el infierno con luz, y así hacer mucho daño al reino oscuro y a sus habitantes:

[...] Tibi, pessime mundi

arbiter, inmittam ruptis Titana cavernis,

et subito feriere die. Paretis, an ille

conpellandus erit, quo numquam terra vocato

non concussa tremit $[\ldots]$.

(6. 742-746)

Como ya observó Emanuele Narducci, Lucano asocia la fuga solis con el crimen (nefas) de la Guerra Civil al igual que Séneca la asocia con el crimen de $\mathrm{Atreo}^{3}$. Por esta razón, el poeta menciona "la noche de Micenas" en dos lugares absolutamente cruciales en la Farsalia: en el primer libro, en el cual describe los augurios siniestros anticipadores del comienzo de la Guerra Civil (1. 540-544); y en el séptimo, describe la batalla de Farsalia que resulta decisiva en la guerra:

[...] Astra Thyestae

intulit et subitis damnauit noctibus Argos [...].

(7. 451-452)

Esto indica claramente que la combinacion de las expresiones mutato sole y tellurem nihil timentem no es ni casual ni está libre de doble significado.

El supuestamente irónico carácter del proemio ha sido el tema de discusión de varios filólogos durante muchos años ${ }^{4}$. Mientras unos, como Berthe Marti ${ }^{5}$ han notado un rastro satírico en el elogio a Nerón; otros, entre ellos Pierre Grimal ${ }^{6}$,

${ }^{3}$ E. Narducci, La provvidenza crudele. Lucano e la distruzione dei miti angustei, Giardini, Pisa 1979, p. 51-74.

${ }^{4}$ B. Marti, The Meaning of the Pharsalia, "American Journal of Philology" 66, 7 (1945), p. 352-376; J.R. Jenkinson, Sarcasm in Lucan i. 33-66, "Classical Review" 24, 1 (1974), p. 8-9; P. Grimal, Is the Eulogy of Nero at the Beginning of the Pharsalia Ironic?, [en:] Oxford Readings in Classical Studies. Lucan, ed. Ch. Tesoriero, Oxford University Press, Oxford-New York 2010, p. 59-68; S. Bartsch, Ideology in Cold Blood. A Reading of Lucan's Civil War, Harvard University Press, Cambridge (MS)-London 1997, p. 173-174 (nota 46).

${ }^{5}$ B. Marti, op. cit., p. 374.

${ }^{6}$ P. Grimal, op. cit., p. 68. 
J. R. Jenkinson ${ }^{7}$ y Sergio Casali ${ }^{8}$ prácticamente excluyen esta posibilidad. Según Narducci, el proemio tiene un carácter convencional y se parece mucho a otros proemios de este género9. Narducci también escribió que la extraña mezcla entre las alabanzas al princeps, y así como la actitud negativa a Julio César y a su exitoso atentado contra la libertad Repúblicana, es algo normal en el contexto de obras como la Apocolocynthosis de Séneca ${ }^{10}$.

Sin embargo, hace poco Lee Fratantuono ${ }^{11}$ y Henry Day ${ }^{12}$ han retomado esta discusión que ya parecía terminada, llegando a conclusiones muy parecidas a las de Marti: es decir, que el proemio está lleno de una "ironía deliciosa"13. Los argumentos de Fratantuono también convencen bastante. Ya sólo por el mero hecho que Lucano llame al joven emperador Caesar, asociándolo de esta manera con Julio César - que es a la vez el personaje malvado de la Farsalia - parece muy sospechoso ${ }^{14}$. Nerón fue descendiente de la dinastía comenzada por Julio César; el mismo que según Lucano, fue el "Atreo" de la historia Romana ${ }^{15}$ y el asesino de la libertad.

Por consiguiente, la mención de la futura deificación de Nerón, o sea, el aparentemente "buen" César (1.45-47): además de crear siniestras asociaciones con la muerte y divinización del primer César - y así como también del mítico Rómulo - también, implica la eminente muerte de Nerón ${ }^{16}$. Por supuesto, la asociación histórica del "buen" Nerón con el "malvado" César está disimulada bajo un elaborado camuflaje de elogios y halagos al joven emperador que aparentemente borra los pecados de su vil antepasado ${ }^{17}$.

No obstante, a pesar de este gran sofisticado camuflaje es obvio que Lucano se refiere directamente a Nerón como el causante de mutatio solis, el cual a su vez, origina el "motín de la tierra". Como ya hemos visto, en la Farsalia este tema está estrictamente conectado con la persona de Julio César. Como resultado, la imagen de Nerón como sucesor de Julio César inevitablemente hace que el elogio sea profundamente irónico.

7 J.R. Jenkinson, op. cit., p. 9.

8 S. Casali, The Bellum Civile as an Anti-Aeneid, [en:] Brill's Companion to Lucan, ed. P. Asso, Brill, Leiden 2011, p. 81-110, en 90.

9 E. Narducci, op. cit., p. 23.

10 Ibidem, p. 24-26.

11 L. Fratantuono, Madness Triumphant. A Reading of Lucan's Pharsalia, Lexington Books, Lanham 2012, p. 11.

12 H. Day, Lucan and the Sublime: Power, Representation and Aesthetic Experience, Cambridge University Press, Cambridge 2013, p. 173.

13 L. Fratantuono, op. cit., p. 11.

14 Ibidem, p. 11.

15 E. Narducci, op. cit., p. 54-58.

16 L. Fratantuono, op. cit., p. 11.

17 Ibidem, p. 8. 


\section{Götterdämmerung}

La fuga solis y el "motín de la tierra" simbolizan el caos que, como ya escribió Jamie Masters, domina sobre el mundo representado en la Farsalia ${ }^{18}$. El regreso del caos al mundo no sólo hace que despierten las fuerzas ctónicas, sino también causa la decadencia de las divinidades olímpicas: es decir, justamente las que tradicionalmente formaban la "maquinaria divina" de los poemas épicos. Los tramas de la Iliada, la Odisea y la Eneide son estrictamente guiados por los dioses olímpicos.

Cada uno de estos fuertes y poderosos dioses representan la causa de alguna nación apoyando su expansión territorial y aumentando las posibilidades de su futuro desarollo. De esta manera, en la Iliada y Odisea Atena es la protectora de los Griegos y consecuentemente, de Odiseo; mientras que en la Eneide, Juno representa a los Latinos al igual que Venus a su hijo Eneas y al resto de los Troyanos. Los dioses velan por el destino de las naciones particulares representadas por sus correspondientes héroes.

La Farsalia, en cambio, no cuenta la historia del crecimiento o expansión territorial de una nación, sino todo lo contrario: es una crónica poética de la autodestrucción de esta nación. Mientras que en la Eneide Roma estaba naciendo a costa de otras tribus Italianas; en la Farsalia, simplemente, se está autodestruyendo. Por eso, la autodestrucción de la República Romana sería la única causa que pudiera ser apoyada por alguna fuerza sobrenatural.

Las divinidades capaces de representar tal causa deberían ser malvadas, destructivas y estar relacionadas con el caos. Deberían, asimismo, enfrentarse con otros seres sobrenaturales que representan las tendencias contrarias a su "causa": o sea, todo lo constructivo. Los dioses "tradicionales" que representaban todo lo bueno de la República están en decadencia puesto que la República lucha contra sí misma y se autodestruye.

La primera señal de que no sólo su poder, sino también su existencia está en peligro se encuentra en el primer libro de la Farsalia donde los dioses lloran y los Lares sudan de miedo al saber que la guerra es inevitable:

Indigetes flevisse deos, urbisque laborem testatos sudore Lares, delapsaque templis dona suis, dirasque diem foedasse volucres accipimus, silvisque feras sub nocte relictis audaces media posuisse cubilia Roma.

(1. 556-560)

18 J. Masters, Poetry and civil war In Lucan's Bellum Civile, Cambridge University Press, Cambridge 1992, p. 65; Ch. Martindale, Redeeming the Text: Latin poetry and the hermeneutics of reception, Cambridge University Press, Cambridge 1993, p. 53; J. Wildberger, Quanta sub nocte iacet nostra dies (Lucan. 9, 13f.) - Stoizismen als Mittel der Verfremdung bei Lucan, [en:] Lucan im 21. Jahrhundert, ed. Ch. Walde, Walter de Gruyter, München-Leipzig 2005, p. 56-88, en 73. Véase también: M. Lapidge, Lucan's Imagery of Cosmic Dissolution, "Hermes" 107, 3 (1979), p. 344-370. 
Esta imagen tan grotesca lo dice todo del concepto de Lucano sobre la religión: la existencia de los dioses "tradicionales" - R.J. Getty explica el adjetivo indigentes como "nativos de Roma"19 - depende, sólo y exclusivamente, de las acciones humanas $^{20}$. Una vez que la causa representada por estos dioses está perdida, automáticamente estos se convierten en unas estátuas ridículas sin ningún tipo de sentido.

Otro ejemplo evidente de la decadencia y, a la vez, de la vanidad de la religión tradicional es la extinción del oráculo de Delfos. En el tercer libro de la Farsalia, Femonoe dice abiertamente que: "Apolo mudó para siempre" (5. 131-132). La Pitia le echa la culpa a la arrogancia de los reyes que, por miedo a oír unos presagios desfavorecidos para con sus propósitos, prohibieron a los dioses hablar:

\section{[...] Non ullo saecula dono nostra carent maiore deum, quam Delphica sedes quod siluit, postquam reges timuere futura et superos vetuere loqui [...].}

(5. 111-114)

De ahí que salga un hecho absurdo: Apolo, el antiguo dios de la profecía que como se suponía en el pasado, tenía muchísimo poder sobre los asuntos humanos, de repente, se deja intimidar por ellos mismos hasta tal punto que, todo indignado, abandona su oficio. Cuando de repente Apio Claudio le presta atención y exige una profecía, Apolo ceba toda su frustración acumulada durante siglos de desprecio, en Femonoe:

\footnotetext{
Qualis in Euboico vates Cumana recessu, indignata suum multis servire furorem gentibus, ex tanta fatorum strage superba excerpsit Romana manu, sic plena laborat Phemonoe Phoebo, dum te, consultor operti Castalia tellure dei, vix invenit, Appi, inter fata diu quaerens tam magna latentem.
}

(5. 183-189)

El Götterdämmerung en la Farsalia es, a la vez, el resultado y la metáfora del desequilibrio cósmico así como del regreso del caos. Simultáneamente la tierra, que hasta ahora permanecía silenciosa, empieza a amotinarse al librarse de todo su temor. Entre las manifestaciones de su "motín" están tanto los cataclismos naturales, descritos en el primer libro, como el diluvio en Ilerda y el comportamiento extraño del agua y de los vientos ${ }^{21}$.

${ }^{19}$ De Bello Civili Liber 1, ed. R.J.Getty, Cambridge University Press, Cambridge-New York 2013, p. 104.

${ }^{20}$ Sobre el ateismo de Lucano véase: A. Augoustakis, Ritual and Religion in Flavian Epic, Oxford University Press, Oxford 2013, p. 150.

${ }^{21}$ M. Lapidge, op. cit., p. 368-369. 


\section{El anti-Olimpo de Lucano}

\section{a. Erichtho}

Mientras los dioses olímpicos pierden su importancia el mundo, sumergido en la noche y el caos, adquiere unos nuevos representantes sobrenaturales. La primera de estos personajes es Erichtho: la espantosa bruja Tesaliense que personifica el caos y la destrucción. Malvada y repulsiva no sólo es capaz de revivir a los muertos y vaticinar el futuro; sino también, de intimidar a los dioses para que le concedan todo lo que ella desea:

Omne nefas superi prima iam voce precantis concedunt carmenque timent audire secundum.

(6. 527-528)

Erichtho está estrictamente relacionada con el elemento de la tierra ya que su propio nombre consiste de las palabras griegas: č $\rho \iota \varsigma$, que significa "discordia"; y $\chi \theta \omega \dot{v}$, "tierra". Este nombre define lo que realmente es Erichtho: la representante, y a la vez, la personificación de la Guerra Civil, o sea, "la que ha nacido de la tierra en época de discordia". Se puede decir que Erichtho es la diosa de la Guerra Civil. Su impávida naturaleza y su odio a la luz del sol están reflejados en el verso 1. 49, citado al principio de este artículo:

telluremque nihil mutato sole timentem $[\ldots]$.

Al igual que Pitón y los demás monstruos ctónicos Erichtho es la hija de la tierra Tesaliense fertilizada por el espíritu de la guerra puesto que el nombre Mars, utilizado aquí por Lucano, obviamente se refiere a la idea de "guerra"; y no, al dios Marte:

Hac tellure feri micuerunt semina Martis.

(6. 395)

La palabra tellus es la traducción latina de la griega $\chi \theta \omega ́ v$; mientras que la palabra Mars, de épıs. De esta manera, Lucano ha explicado la etimología del nombre de la bruja:

Tellus Martis

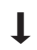

Martis-tellus $=\dot{\varepsilon} \rho \imath-\chi \theta \dot{\omega} v$ 
Este compuesto de las palabras "tierra" y "discordia" también implica otro significado: "campo de batalla"; por eso, Erichtho se ocupa de rebuscar entre los cadáveres para practicar su ars polluta (6. 509). La descripción de este arte corresponde evidentemente con el siguiente fragmento del proemio de la Farsalia:

unde tuam videas obliquo sidere Romam.

Aetheris inmensi partem si presseris unam, sentiet axis onus. Librati pondera caeli orbe tene medio; pars aetheris illa sereni tota vacet nullaeque obstent a Caesare nubes.

$(1.55-59)$

[...] Tenet ora profanae

foeda situ macies, caeloque ignota sereno

terribilis Stygio facies pallore gravatur inpexis onerata comis: si nimbus et atrae sidera subducunt nubes, tunc Thessala nudis egreditur bustis nocturnaque fulmina captat.

(6. 515-520)

Las similitudes entre estos dos fragmentos son suficientemente obvias para deducir que Lucano ha incluído en el proemio unas alusiones muy obvias al episodio Tesaliense, y al mismo tiempo, muy poco favorables al emperador. El nuevo "César" ya deificado se encuentra en el cielo sereno; mientras que la tierra, que se encuentra por debajo de su carro Apolínico, sigue submergiéndose cada vez más en la oscuridad que le quita todos sus frenos y la estimula a producir terribles monstruos. Así como César, Nerón produce el mismo efecto y la historia se repite.

\section{b. Anteo}

Mientras Erichtho es la única criatura ctónica "real", nacida en tiempos históricos, Lucano también relata historias de otros personajes parecidos: igual de monstruosos que ella, que surgieron de la tierra en tiempos míticos y en circunstancias de conflicto. Uno de ellos es Anteo, el hermano menor de los Gigantes:

Nondum post genitos Tellus ecfeta gigantas terribilem Libycis partum concepit in antris. Nec tam iusta fuit terrarum gloria Typhon aut Tityos Briareusque ferox; caeloque pepercit quod non Phlegraeis Antaeum sustulit arvis.

(4. 593-597) 
Los Gigantes nacieron cuando Crono mutiló y derrocó a su padre Urano (cielo) cuya sangre fertilizó a Gea (tierra) y después de ellos (post... 4. 593) la tierra dio a luz al horrible y guerrero Anteo. Al igual que Erichtho - cuyo nombre es

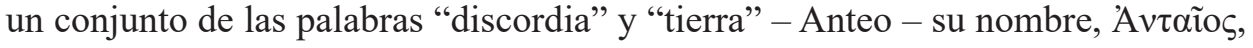
significa en griego "hostíl" - fue concebido por la tierra en época de discordia, es decir, poco tiempo después de la Gigantomaquia.

Igualmente que el excurso de Erichtho, el de Anteo también está aludido en el proemio. Day ha descubierto que este excurso está conectado con el proemio a través del motivo de la Gigantomaquia ${ }^{22}$ :

Quod si non aliam venturo fata Neroni invenere viam magnoque aeterna parantur regna deis caelumque suo servire Tonanti non nisi saevorum potuit post bella Gigantum, iam nihil, o superi, querimur; scelera ipsa nefasque hac mercede placent $[\ldots]$.

(1. 33-38)

Según Day, Lucano supuestamente contrapone al "buen" Nerón con la maldad de los Gigantes que son asociados con César y, a través de esto, con el propio Nerón; por eso la apoteosis de Nerón desequilibra el universo ${ }^{23}$. Esta interpretación resulta ser perfectamente lógica a la luz de la siguiente parte del proemio donde Lucano deja de referirse al emperador como Nero, llamándole Caesar; y de esta manera, asociándolo con Julio César.

La apoteosis de César y sus descendientes tiránicos desequilibra el universo de la misma manera que la intrusión de los Gigantes al Olimpo. Las conexiones entre el proemio y los excursos de Erichtho y Anteo funcionan de una manera parecida. Muy sútilmente transmiten el siguiente mensaje: el desequilibrio del universo causado por la "Gigantomaquia" de la Guerra Civíl - la cual ha resultado en la intrusión perpétua del impostor y sus descendientes al "Olimpo" - sumerge la tierra en caos.

En la Farsalia, Anteo que es el equivalente mitológico a Erichtho, es uno de los hijos monstruosos de la tierra "amotinada" que simboliza las fuerzas destructivas de origen telúrico que se activan en el momento de una discordia dentro de la misma familia o sociedad. Anteo es la respuesta de la tierra a la Gigantomaquia siendo, a su vez, un Gigante ${ }^{24}$; y así pues por lo tanto también, un representante de la Gigantomaquia. Del mismo modo Erichtho es la respuesta de Tesalia a la Guerra Civil Romana que tiene lugar en este territorio siendo, a su vez, la representante de esta guerra.

${ }^{22}$ H. Day, op. cit., p. 172-173.

${ }^{23}$ Ibidem, p. 173.

${ }^{24}$ P. Asso, A Commentary on Lucan, De Bello Civili, IV. Introduction, Edition, and Translation, Walter de Gruyter, Berlin-New York 2010, p. 220. 


\section{c. Medusa}

Medusa es el tercer monstruo ctónico en la Farsalia que, al igual que Erichtho, es una mujer destructiva con unos poderes sobrenaturales; e igual que Anteo, es un personaje mítico de proveniencia ctónica (9.624-628). Medusa es la hija de Forcis y Ceto siendo Forcis el hijo de Gea (tierra) ${ }^{25}$ y Ponto (mar). Por esta razón, el excurso comienza con la insinuante imagen de la tierra hirviendo que es penetrada por el océano (fervida tellus / accipit Oceanum, 9. 624-625). ${ }^{26}$ Aunque Medusa no es la hija sino la nieta de la tierra, sus lazos con ella son casi tan fuertes como los de Anteo.

Este excurso, también, está conectado con el proemio a través del motivo del vuelo sobre la tierra. Perseo vuela sobre la tierra antes (volucri ... fratri, 9. 665; averso ... volatu, 9. 668) y después de matar a Medusa (aliger in caelum sic rapta Gorgone fugit, 9. 684). Las consecuencias de su regreso son terribles ya que la cabeza del monstruo, que Perseo está llevando, gotea sangre venenosa de la cual nacerán infinidades de serpientes ${ }^{27}$.

Así como el vuelo del victorioso Perseo causa el nacimiento de unas serpientes muy venenosas, o sea, de otros monstruos telúricos; también, el deificado Nerón en el proemio vuela al cielo en el carro de Apolo (astra petes serus, 1. 45; flammigeros Phoebi conscendere currus, 1. 48) y desequilibra el universo. Por eso, el poeta aconseja al emperador que no descuide la simetría del eje:

Aetheris inmensi partem si presseris unam, sentiet axis onus. Librati pondera caeli orbe tene medio; $[\ldots]$.

(1. 56-58)

La imagen de Nerón endiosado volando en el carro de Apolo sobre la tierra sumergida en oscuridad y liberada de todo temor (telluremque nihil mutato sole timentem, 1.49) corresponde de una manera muy lógica con el siguiente fragmento del excurso sobre Medusa, en el cual las gotas de sangre del monstruo caen a la tierra de Libia cuando Perseo vuela sobre ella por la noche:

[...] Zephyro convertitur ales

itque super Libyen, quae nullo consita cultu

sideribus Phoeboque vacat: premit orbita $\underline{\text { solis }}$

exuritque solum; nec terra celsior ulla

nox cadit in caelum lunaeque meatibus obstat,

si flexus oblita vagi per recta cucurrit

signa nec in Borean aut in Noton effugit umbram.

${ }^{25}$ Es decir, es un dios ctónico.

${ }^{26}$ Hom. Il. 21, 195-197, Hes. Th. 127-136. La expresión utilizada por Lucano tiene obviamente un significado erótico.

${ }^{27}$ Para la cuestión de los efectos desastrosos del vuelo de Perseo véase también: M. Malamud, Pompey's Head and Cato's Snakes, Classical Philology 98, 1 (Jan., 2003), p. 31-44, en 31. 
Illa tamen sterilis tellus fecundaque nulli arva bono virus stillantis tabe Medusae concipiunt dirosque fero de sanguine rores, quos calor adiuvit putrique incoxit harenae.

(9. 689-699)

Las similitudes lexicales entre ambos fragmentos confirman esta interpretación:

[...] Te, cum statione peracta

astra petes serus, praelati regia caeli

excipiet gaudente polo: seu sceptra tenere

seu te flammigeros Phoebi conscendere currus

telluremque nihil mutato sole timentem

igne vago lustrare iuvet, tibi numine ab omni

cedetur, iurisque tui natura relinquet

quis deus esse velis, ubi regnum ponere mundi.

(1. 45-52).

Así como Anteo nace de la sangre del mutilado Urano, también las serpientes nacen de la sangre de la mutilada Medusa. Ambos personajes, tanto Urano como Medusa, sufren un acto de violencia que consiste en la mutilación de sus cuerpos y da como resultado el nacimiento de unas criaturas monstruosas, una vez que su sangre entra en contacto con la tierra, volviéndose en semillas de la destrucción. El nacimiento de Medusa, al contrario que el de Anteo, no está explicado por el poeta como producto de una guerra; sin embargo, existe una versión del mito consolidada por Eurípides, según la cual, Gea produjo a Medusa durante la Gigantomaquia para que aquella ayudara a sus hijos, los Gigantes, en la lucha contra los dioses olímpicos (Eur. Ion. 988-1006).

Lo interesante en este fragmento es que Eurípides menciona también a Erictonio (v. 999), el primer rey de Atenas, el cual nació de la tierra con el semen de Hefesto cuando éste intentó violar a Atena. A pesar de que el nombre de Erictonio no proviene de la palabra éplৎ (discordia), sino de éplov (lana ${ }^{28}$ y $\chi \theta \omega ́ v$; sin embargo, suena muy parecido al nombre de Erichtho. La coincidencia del nombre de Erictonio con el aition de Medusa que encaja en el paisaje mitológico de la Farsalia, es verdaderamente interesante.

\section{Conclusión}

Los poemas épicos anteriores a la Farsalia como las epopeyas griegas o la Eneide de Virgilio suelen narrar historias de expansión tanto territorial como personal de unos héroes, los cuales son guiados hacia el desarollo y la prosperidad

${ }^{28}$ Atena se limpió el muslo donde cayó el semen con un trozo de lana, el cual acto seguido tiró al suelo. Cuando nació Erictonio, Atena lo metió en una caja donde creció en secreto. 
por uno o más personajes divinos. La Farsalia, en cambio, es un poema sobre la decadencia y autodestrucción de la República Romana.

Por lo tanto, no necesita de ningún guía sobrenatural para que cuide de su desarollo; todo lo contrario, ya desde el principio del poema Lucano acentúa el hecho de que la época de los dioses "tradicionales" se acabó junto con la República. Entre las manifestaciones más evidentes de este Götterdämmerung están los presagios del primer libro, la extinción del oráculo Délfico, y, finalmente, el hecho de que los dioses olímpicos se dejen intimidar por personajes como Erichtho.

La sustitución tan obvia del oráculo Apolínico por una bruja conectada con la tierra tiene una función simbólica al ser la antítesis exacta al mito griego en el cual Apolo derrotó y mató a Pitón, un monstruo ctónico parecido a una serpiente, y acto seguido se hizo con la grieta en la roca en Delfos. Lucano menciona esta leyenda justo antes del excurso Délfico (5. 79-85).

En la mitología griega Pitón era un mónstruo ctónico que simbolizaba el caos; mientras que Apolo, al ser un dios olímpico, representaba el orden y la harmonía. El mundo de la Guerra Civil está sumido en caos: por lo tanto, los representantes olímpicos divinos simplemente no son adecuados para él; en cambio, las criaturas parecidas a Pitón, que simbolizan la discordia ${ }^{29}$, lo representan de una manera muy adecuada.

Lógicamente, la Farsalia carece de "maquinaria divina" tradicional de la poesía épica; no obstante, desarrolla a cambio un nuevo "panteón" totalmente anti-olímpico que consiste solamente de monstruos ctónicos. Dos de aquellos, es decir Anteo y Medusa, pertenecen al pasado mitológico y su función en el poema es meramente ilustrativa; pero Erichtho, que vive en el presente del "aquí y ahora" de la Farsalia, derrota a los dioses tradicionales - ya inactuales e inadecuados - y ocupa su lugar en un mundo devastado por la guerra.

No sólo el nombre de Erichtho, sino también toda su existencia depende estrictamente de la tierra y la discordia. La bruja vive en un mundo lleno de serpientes, hierbas tóxicas y, por lo general, de todas las cosas conectadas con el elemento tierra; por lo tanto, puede decirse que es una diosa ctónica. Al mismo tiempo, vive también de la guerra, la cual le aporta los cadáveres necesarios para su "arte poluta".

La bruja tesaliense aunque tiene una función muy parecida a la de los dioses olímpicos en la poesía épica griega y latina anterior a la Farsalia; pero al contrario a ellos, que contribuyen a los éxitos de sus protegidos, resulta ser en realidad totalmente inútil para el curso de la guerra ya que su único oficio es el de nutrirse y gozar del caos general. Por todo esto, puede decirse, también, que Erichtho es la diosa representante de la nada existente.

${ }^{29}$ J. Masters, op. cit., p. 176. 
El punto de partida del presente artículo es la expresión telluremque nihil mutato sole timentem en el verso 1.49. El análisis detallado de este verso y sus posteriores repercusiones en la Farsalia puede haber revelado que este verso junto con todo el fragmento del proemio al cual pertenece; además de anunciar los tres excursos ctónicos, también delata la actitud muy poco favorable del poeta al emperador, el cual resulta ser identificado con Julio César: es decir, el causante del caos descrito en la Farsalia. 